\title{
As viagens, a liberdade e o mundo árabe na obra de Isabelle Eberhardt
}

\author{
Cristiane Grando
}

Como Isabelle Eberhardt, sinto especial amor pelas viagens. Numa de minhas idas para a França, além de ler novos nomes da literatura, conheci uma professora de espanhol, a quem agradeço: Espérance Aniesa, amiga-irmã que me acompanha desde os primeiros passos como tradutora e que me ajudou a esclarecer várias dúvidas de francês ao traduzir estas notas de viagem. Agradeço igualmente ao Prof. Dr. John Milton por sua leitura e correções. Em outra viagem, ao participar de um congresso na Universidade Federal de Uberlândia como organizadora de um Grupo de Trabalho (GT) sobre Hilda Hilst, conheci Giovana Bleyer, hoje estudante de doutorado em tradução literária, que me estimulou a pesquisar sobre a literatura suíça. A partir desse momento passei a ser leitora de Isabelle Eberhardt (17 de fevereiro de 1877, Genebra, Suíça - 21 de outubro de 1904, Aïn-Sefra, Argélia), escritora suíça de nacionalidade francesa pelo casamento, filha ilegítima, nascida de mãe russa, Nathalie Moerder (nascida Eberhardt), exilada e casada com o general Pavel de Moerder; e de pai nascido na Armênia, Alexandre Trofimowsky, apelidado Vava, anarquista e ex-monge convertido ao islamismo.

Eberhardt se instala com sua mãe em 1897 em Bône, na Argélia. Luta contra o poder colonial francês, decide viver como muçulmana e se veste como se fosse um homem argelino. Depois da morte de sua mãe, viveu vários meses como nômade e conheceu Slimane Ehnni, muçulmano de nacionalidade francesa, com quem se casou em 1901. Na Argélia, colaborou com o jornal El Akbbar, dirigido por Victor Barrucand. Foi enviada a Aïn Sefra como repórter de guerra na fronteira marroquina. Em 1903, em Beni Ounif, conheceu o general 
Lyautey, que valoriza a sua compreensão da África e seu sentido da liberdade. Em 21 de outubro de 1904 uma forte tempestade se abateu sobre Aïn Sefra, atingindo a casa onde ela residia. Slimane conseguiu sobreviver; Isabelle não. Seus restos mortais descansam num pequeno cemitério muçulmano em Aïn Sefra. Eberhardt é autora de uma dezena de obras póstumas que apresentam a realidade quotidiana da sociedade argelina no período da colonização francesa. Seus diários de viagens retratam suas impressões de nômade no Saara.

Saindo da Europa e da África, hoje Isabelle Eberhardt chega na América do Sul viajando através das primeiras dez páginas das suas "Notas de viagem: Marrocos-Argélia-Tunísia" (Notes de route: Maroc-Algérie-Tunisie), que apresentaremos a seguir.

Sobre os árabes no Brasil, Patrícia Mariuzzo (2011) afirma:

Após um período de declínio, a partir dos anos 1970, há uma nova onda migratória de árabes para o Brasil, muçulmana em sua maioria. Os imigrantes deixaram suas nações motivados, sobretudo, pela guerra civil libanesa, pelas guerras árabe-israelenses e pela ocupação israelense dos territórios palestinos e do sul do Líbano. "Com isso, diversas mesquitas foram erguidas em vários estados: Rio de Janeiro, Minas Gerais, Paraná, Mato Grosso, Goiás. A partir de 1990 cresce também o número de brasileiros convertidos ao Islã. O português passou a ser adotado no sermão das sextas-feiras em comunidades muçulmanas como a do Rio de Janeiro, com grande número de convertidos, ao mesmo tempo em que é crescente a oferta de cursos de língua árabe”, explica o pesquisador [Oswaldo Truzzi, em artigo para a Revista de História da Biblioteca Nacional. Os muçulmanos demoraram a criar instituições religiosas no Brasil, provavelmente porque preferiram não mobilizar representações estigmatizantes do islã que circulavam na sociedade. A primeira mesquita construída na América Latina, em 1929, fica no Brás, não por acaso, tradicional bairro de comércio popular na capital paulista e um reduto de influência da cultura árabe no Brasil. As práticas religiosas buscavam conciliar a diversidade no interior da comunidade árabe, permitindo que eles construíssem uma moral, pautada pela observância dos costumes e tradições impostos pela religião.

A tradução de Eberhardt que apresentaremos exigiu pesquisas geográficas, de personagens históricos e de algumas questões de cultura africana. As possíveis dificuldades de compreensão por parte do leitor brasileiro se dão em especial se consideramos que pouco se estuda sobre o continente africano em período de formação escolar e, em certos casos, até mesmo universitária. 
A seguir leremos resultados das referidas pesquisas, separados em três blocos, sempre apresentando os dados em ordem de aparição no texto de Isabelle Eberhardt.

\section{Dados geográficos}

1.1. Orã ou Orão é uma província da Argélia cuja capital, chamada Orã, é a segunda maior cidade do país e está situada no litoral mediterrâneo argelino.

1.2. Argélia ou Algéria, oficialmente República Argelina Democrática e Popular, é um país da África do Norte que faz parte do Magrebe. Sua capital é Argel, no norte do país, na costa do mediterrâneo. Argel, Orã e Constantina são as principais cidades. Com uma superfície de $2.376 .400 \mathrm{~km}^{2}$, é o maior país próximo ao Mediterrâneo e o mais extenso da África, após a divisão entre o Sudão e o Sudão do Sul. Partilha suas fronteiras terrestres ao nordeste com a Tunísia, ao leste com a Líbia, ao sul com o Níger e o Mali, ao sudoeste com a Mauritânia e o território contestado do Saara Ocidental, e ao oeste com o Marrocos. A Argélia está dividida atualmente em 48 coletividades públicas territoriais chamadas wilayas (províncias), subdivididas em 160 daïras (subprefeituras) formadas por 1.541 baladiyah (comunas). A divisão administrativa do território tem sido modificada ao longo do tempo desde a independência do país.

A Argélia passou a ser membro da Organização das Nações Unidas (ONU), da União Africana (UA) e da Liga Árabe logo depois de sua independência em 1962. Integra a Organização dos Países Exportadores de Petróleo (OPEP) desde 1969. Em fevereiro de 1989, a Argélia criou, com outros Estados magrebes, a União do Magrebe Árabe (UMA). Em 2008 aderiu à União pelo Mediterrâneo.

A Constituição argeliana define "o islã, o árabe e o berbere" como "componentes fundamentais" da identidade do seu povo e o país como "a terra do Islã, parte integrante do Grande Magrebe, país árabe, mediterrâneo e africano".

1.3. Argel é a capital e maior cidade da Argélia, apelidada de Alger la Blanche ("Argel a Branca") pela admirável aparência do branco resplandecente dos edifícios das encostas vistos do mar.

1.4. Aïn Sefra ou Aïn Safra é uma comuna da província de Naâma, na Argélia.

1.5. Mustafá (em francês: Mustapha) é a denominação de uma parte do subúrbio sul de Argel, capital da Argélia.

1.6. Perrégaux, antigo nome de Mohammadia, é uma comuna da província de Mascara situada a $80 \mathrm{~km}$ ao sudeste de Orã, a $35 \mathrm{~km}$ ao norte de Mascara, a $40 \mathrm{~km}$ de Mostaganem e a $57 \mathrm{~km}$ de Relizane. 
1.7. Aræew ou Arzen é uma comuna da Argélia, pertencente à província de Orã. 1.8. O Tell algeriano é uma zona fértil formada pela área imediatamente ao sul da costa do país. A maior parte dessa área costeira é acidentada, até mesmo montanhosa, e há poucos portos bons. A Argélia é formada por duas regiões geográficas principais: a região norte; e, ao sul, a região do deserto do Saara. A região norte é formada por quatro zonas: 1) uma pequena faixa de planície acompanhando a costa do Mediterrâneo; 2) a região da cadeia de montanhas do Atlas, que possui clima mediterrâneo e solo fértil abundante; 3) a região semiárida e parcamente povoada do Chotts, que contém lagos salgados (chotts), onde se localizam em maior número os criadores de ovelhas e cabras; 4) e a região das montanhas do Atlas do Saara, uma série de montanhas e maciços, sendo também uma região semiárida e usada essencialmente como pastagem. O Atlas telliano, ao norte, forma com o Atlas saariano, que vem do sul, dois conjuntos de relevos paralelos que se aproximam e vão em direção ao leste, e entre os quais se intercalam vastas planícies e altos platôs. Os dois Atlas tendem a se confundir no leste da Argélia. A faixa do Tell, com uma largura de 80 a $190 \mathrm{~km}$, estende-se sobre aproximadamente $1.622 \mathrm{~km}$ da costa mediterrânea e está formada por cadeias de montanhas (Ouarsenis, Chenoua, Djurdjura, Babors e Bibans) ao longo do litoral, frequentemente separadas por vales de flora e fauna ricas que abrigam riachos, como é o caso do vale do Chelif e do vale da Soummam. O monte Lalla-Khadîdja, em Kabylie, onde as montanhas estão cobertas de neve no inverno, é o ponto culminante e tem 2.308 metros de altitude. As planícies do Tell abrigam, juntamente com os vales adjacentes, a maior parte das terras férteis da Argélia.

1.9. Saïda é uma cidade argelina, capital da província homônima.

1.10. Alfa: segundo Corrêa (1986), "gramínea da Argélia". Na definição 4 do Dicionário Houaiss da Lingua Portuguesa, "planta (Stipa tenacissima) da família das gramíneas, nativas do Oeste do Mediterrâneo, de caules fibrosos, muito usada para fabricar papel, cordas, velas de barcos, esteiras etc.; esparto".

1.11. Djebel Antar é o ponto culminante da cadeia de montanhas que rodeia Béchar, na região da Saoura (Argélia). Sua altitude é de 1.953 metros.

1.12. Meknès-Tafilalet é uma região do Marrocos. Sua capital é a cidade de Meknès.

\section{Personagens históricos}

2.1. Abd El-Kader ou Abd Al-Kader: Mascara-1808 - Damasco-1883, foi um sultão árabe que dirigiu a luta contra os franceses na Argélia. Foi vencido em Orã, 
mas um tratado assinado com o general Desmichels lhe assegurou um reino em torno de Mascara (1834). A posse da província de Orã e de parte da província de Argel, reconhecida por Bugeaud pelo Tratado de Tafna (1837), não impediu que voltasse à luta em 1839. Os franceses venceram e ocuparam toda a Argélia. A tomada de sua smala pelo duque de Aumale (1843) e a derrota do seu aliado, o sultão do Marrocos, em Isly (1844), o obrigaram a se render ao general Lamoricière. Refugiou-se então na França até 1852, período em que se tornou amigo dos franceses. Retirou-se em seguida para Brousse (1853) e para Damasco (1855), onde ficou até a sua morte. Seus restos mortais foram transferidos para a Argélia em 1966.

2.2. Cheikh Bouamama ou Boumama, ou Bou Hamama, ou Bou-Amama, cujo nome completo é Mohammed Ibn Larbi Ibn Cheikh Ibn Mohammed Ibn Brahim Ibn Attaj Ibn Sidi Cheikh Abdelkader, nasceu em 1833 ou em 1840 em Figuig, no Marrocos, e morreu em 1908 em Aioun Sidi Mellouk, na região de Oujda, também no Marrocos, perto da fronteira algeriana. É uma figura histórica, um combatente reconhecido e personagem místico. Pertence ao ramo dos Ouled Sidi Cheikh. Cheikh "Bouamama" foi nomeado assim, pois durante toda a sua vida usou um turbante (âmama) sobre a cabeça, parecendo-se, neste aspecto, a todos os árabes e evocando sua piedade e apego ao islamismo. Ele conseguiu pôr fim a divergências tribais de sua época e constituiu sua base militar na rota de Naâma e Abiodh Sidi Cheikh (ex-Geryville). Como habilidoso líder, dirigiu a resistência contra o colonialismo na Argélia de 1881 a 1908, participando de numerosas batalhas e causando importantes perdas aos inimigos. Combateu até o ano de sua morte.

\section{Outras questões}

3.1. Batalha de El-Moungar: campanha de pacificação do Marrocos.

3.2. Douars: pequenas cidades formadas por tendas pelos árabes nômades.

3.3. Mokhazni é um funcionário público não ligado à administração colonial francesa e que pertencia ao makhzen (ver 3.7).

3.4. Spabi: O uniforme dos atiradores à oriental remonta à criação dos primeiros regimentos nos anos 1840. Este uniforme, exceto na escolha das cores, é quase idêntico àquele dos zuavos e dos spahis (unidades de cavalaria pertencentes às Forças Armadas da África, que dependia do Exército-de-Terra francês), compreendendo: um penteado chamado "chéchia" ou "chèche"; uma vestimenta de cor azul com os tapumes amarelos, usada sobre um "sédria" (colete); um cinto de 
lã vermelha; o "séroual", ou seja, uma calça azul ou branca, ampla, com numerosas pregas.

3.5. Raz̧ia: "invasão de território inimigo ou estrangeiro em incursão rápida para saque de rebanhos, cereais, pessoas"; "malefícios, depredações, ruína contra valores materiais ou espirituais, praticados por grupo contra grupo ou coletividade", segundo o Dicionário Eletrônico Honaiss da Lingua Portuguesa, de Antônio Houaiss (2009).

3.6. Coupeurs de route, que traduzimos por saqueadores de estrada, são bandos armados que atacam violentamente os automóveis nas estradas. Suas atividades vão de um simples roubo a sequestros, passando por violações e assassinatos. Os “coupeurs de route" agem principalmente nos países da África subsaariana e são normalmente constituídos por combatentes desmobilizados das antigas rebeliões, entregando-se a esta atividade a fim de assegurar sua subsistência.

3.7. Makhžen ou Majzené é uma designação coloquial e tradicional no Marrocos para o Estado e as instituições da monarquia marroquina, como a justiça, administração, forças armadas, polícias, bombeiros. Antes da independência, makhžen era a designação oficial do governo do sultão do Marrocos, que era então um protetorado francês. O termo também foi usado na Tunísia durante o período colonial francês e quando era uma província autônoma otomana.

O makhæ̌en era o conjunto de instituições governamentais dependentes da monarquia, distinguindo-se os seguintes makhzens particulares: makhzen de polícia, de guerra, de proteção, administrativo e de intervenção. Todos os agentes que pertenciam ao makhzen (ou seja, os funcionários públicos não ligados à administração colonial francesa) eram chamados de mokhaznni. Em outra perspectiva, o makhzzen designava a elite que estava mais próxima do poder monárquico, constituída por nobres, empresários, latifundiários, líderes tribais, militares de patentes superiores, chefes de serviços de segurança e outros membros bem relacionados do establishment.

Etimologia: A palavra árabe makhzen (de kazana, "armazenar") significa o mesmo que a palavra portuguesa que nela tem origem: "armazém". O "armazém" a que originalmente o termo se refere era a casa onde os servidores civis do rei ou do sultão recebiam os seus salários. Em árabe marroquino o termo tornou-se sinônimo de uma certa elite. Possivelmente essa conotação é uma metonímia relacionada aos impostos que o governo real (makhzen) cobrava.

O makhžen no Marrocos: Depois da independência e da subsequente criação do estado marroquino moderno, com instituições modernas, a instituição tradicional do makhzen deixou de existir formalmente, passando o termo a designar os 
aspectos mais tradicionalistas e antiquados, com traços de feudalismo, do funcionamento do estado do Marrocos, que contrastam e por vezes se opõem, de forma mais velada ou mais aberta, à democracia formal das instituições marroquinas.

Atualmente, o termo mokhazni é empregado para designar os membros das "Forças Auxiliares", um corpo paramilitar polivalente que depende do Ministério do Interior. O termo relacionado e semelhante, mujazni, designava a polícia do sultão e está na origem da designação informal, por vezes com conotações menos respeitosas à polícia: mujazniyya, pronunciado mjazniyya coloquialmente.

Desde as manifestações de 2011, que constituíram uma espécie de versão marroquina da Primavera Árabe, o termo makhzen passou a ser usado para designar os processos e sistemas arcaicos e tradicionais do sistema político e da monarquia, de que fazem parte, entre outros, o poder de decisão dos conselheiros do rei e dos altos funcionários nomeados por este.

3.8. Agha: chefe superior ao caïd, na Argélia. Um caïd é um funcionário muçulmano competente em matéria administrativa, judiciária e policial.

3.9. Amour ou Amûr de Aïn-Sefra: tribo pertencente a Aïn-Sefra.

\title{
Convite à leitura, convite à viagem...
}

Convidamos o leitor a se embriagar nos movimentos dos mundos europeu e árabe, seguindo os passos e as palavras de Isabelle Eberhard:

\author{
Notes de route: Maroc-Algérie-Tunisie \\ Sud-Oranais \\ Départ d'Alger
}

Ain Sefra, fin septembre 1903.

Les derniers jours de l'été s'égrenaient monotones. Sous l'accablement d'un ciel sans nuages, Alger dormait. Les rues, où les passants étaient rares, semblaient plus larges, et des essaims de mouches bleues bourdonnaient dans l'ombre brève des maisons. Les collines de Mustapha se voilaient de poussières ténues, et les blancheurs laiteuses de la haute ville s'éteignaient. Là, pourtant, dans les ruelles étranglées, la vie continuait ardente, ivre de lumière et de couleur, avec les étalages de fruits et d'étoffes, et le chant pensif des rossignols captifs devant les cafés maures. 
Un lourd ennui pesait sur Alger, et je me laissais aller à une somnolence vague, sans joie et sans chagrin, et qui, sans désirs aussi, aurait pu avoir la douceur de l'anéantissement.

Tout à coup, le combat d'El-Moungar survint, et, avec lui, la possibilité de revoir les régions âpres du Sud: j’allais dans le Sud-Oranais, comme reporter... Le rêve de tant de mois allait se réaliser, et si brusquement!

Le long voyage en chemin de fer, à travers tout l'ouest et le sud-ouest de l'Algérie, fut charmant.

Dans la première émotion joyeuse du départ, j’eus quelques heures de repos et de rêverie.

Il est ainsi, à certaines époques de la vie, des instants où rien d'extraordinaire ne survient, mais qu'on n'oublie jamais dans la suite, car ils sont d'une indicible douceur.

C'était à Perrégaux, où il faut attendre le train d'Arzew qui descend vers le Sud.

Perrégaux n'est qu'un bourg espagnol serti de grands jardins verts, au milieu d'une immense plaine fertile. Pourtant, ce coin très quelconque du Tell algérien me parut souriant, presque beau.

Le jour déclinait, limpide, sur le calme de la campagne. Une haute colline barrait l'horizon qui s'allumait peu à peu. Au sommet, il y avait une petite chapelle de Sidi Abdelkader de Bagdad, qui semblait toute rose, entre quelques silhouettes d'oliviers gris. Là, dans l'herbe desséchée, des pierres brutes se cachaient: le cimetière musulman, un lieu de mélancolie calme, sans rien de funèbre.

... Le soir, j’allais m'étendre sur une natte, devant un café maure. A côté, au-dessus de la porte cochère d'une hôtellerie espagnole, on lisait en gros caractères maladroits: Defendido entrar gitanos, "entrée interdite aux gitanes".

En face, un mur nu se profilait sur l'opale rose du couchant. Accroupis à terre, des Arabes nomades rêvaient. Dans l'air chaud, des senteurs connues traînaient les senteurs du pays bédouin, aux soirs d'été: fumée de thuya ou de genévrier, odeurs de peaux de boucs, de goudron, de chairs bronzées en moiteur. Et moi, je goûtais la volupté profonde de la vie errante, la joie d'être seule, inconnue sous le burnous et le turban musulmans, et de regarder en paix le jour finir en des lueurs rouges sur la simplicité des choses, dans ce village où rien ne me retenait, et que j’allais quitter à la tombée de la nuit.

Après, ce furent de nouveau des heures longues à la fenêtre du wagon, à travers des pays toujours plus déserts et plus âpres, à mesure que le petit train lent descendait vers le Sud. 
Des villages et des bourgs passèrent dans la nuit lunaire, rapides, furtifs, comme des visions.

Vers le milieu de la nuit, ce fut la triste Saïda, où tant d'épaves humaines viennent chercher l'oubli sous la capote anonyme de la légion étrangère. Puis, la rude grimpée des hauts plateaux, sur la voie en lacets. Les deux machines du train s'essoufflaient, hoquetaient comme des bêtes poussives.

En haut, à l'entrée de l'immense plaine nue, deux marabouts jumeaux semblaient monter la garde.

Des haltes en rase campagne, pour des villages qu'on ne voyait pas ou pour de lointains douars: Aïn-el-Hadjar, Bou-Rached, Tafaroua...

Enfin le jour s'alluma, dans un ciel vert et rouge, sur les petites dunes livides du Khreider.

Et ainsi indéfiniment, c'était toujours la monotonie grave, la tristesse, et aussi le grand charme poignant de la plaine du Sud, avec ses rares touffes d'alfa coriace et ses arbrisseaux rampants, gris sur le sol de sanguine. Des chaînes de montagnes fuyaient au loin, à peine distinctes, diaphanes.

Le soleil se leva, et nous arrivâmes en face de l'arête robuste du DjebelAntar s'avançant dans le vague des horizons plats. Au pied de cette haute muraille bleue, ce fut Mechéria, quelques toits roses, quelques maigres arbres jaunis, puis, tout de suite après, plus rien, de nouveau le vide de la steppe où se jouaient les lueurs irisées du matin.

Les gares esseulées avaient, dès le Khreider, changé d'aspect: c'étaient maintenant de hautes petites bastilles flanquées de miradors gris, fermées de lourdes portes en fer.

... Enfin des montagnes surgirent de l'azur chaud des lointains: le DjebelMektar, le Mir-el-Djebel, les monts de Sfissifa. Au delà, vers l'Ouest, c'était le Maroc.

De grandes dunes rougeâtres montèrent à l'assaut du Mektar, comme des vagues déferlantes. Une ceinture de verdure bleuâtre enserra les hauts bâtiments en briques de la redoute.

Vers la droite, quelques maisons sahariennes en toub, ${ }^{1}$ serrées les unes contre les autres, des touffes de figuiers noirs, quelques silhouettes de dattiers, quelques marabouts blancs. Nous stoppions enfin à Aïn-Sefra, où je ne devais que passer.

1 Toub, pisé arabe. 


\section{Aïn-Sefra}

Aïn-Sefra, naguère garnison quelconque plongée dans le sommeil et la routine de la vie militaire en temps de paix. ${ }^{2}$ Aujourd'hui, avec les troubles du Sud et la tourmente qui gronde de nouveau à travers le Maroc en fermentation, AïnSefra semble se réveiller, reprendre ses aspects de jadis, aux temps héroïques de Bou-Amama. Les troupes plus nombreuses, plus bruyantes, les arrivées et les départs, les attentes, parfois des angoisses, tout un mouvement insolite emplit les ruelles de sable.

Se mêlant au soleil, goumiers montés sur de petits chevaux maigres, tout en muscles, mokhazni en longs burnous noirs brodés de rouge sur la poitrine, la ceinture hérissée de cartouches, tirailleurs bleus, spahi au manteau rouge, et les légionnaires, ces hommes blonds du Nord, bronzés, tannés par des soleils lointains, aux colonies.

Dans les cantines et les cafés maures pleins d'un joyeux tapage, les contrastes les plus inattendus se heurtent. Ici, les couplets grivois des chansons à deux sous, les scies récentes, se mêlent aux sentimentalités roucoulantes des romances allemandes ou italiennes. Et à côté la vieille rhaïta ${ }^{3}$ africaine pleure et hurle ses triolets étranges, accompagnant des mélopées lentes, coupées, en guise de refrain, de longs cris désolés.

En une même griserie de mouvement et de bruit, les deux mondes voisins, le monde européen et le monde arabe, se coudoient, se mêlent sans jamais se confondre.

A toutes ces dissonances la légion étrangère vient ajouter encore d'autres notes lointaines. Et avec tout ce tapage et tous ces hommes, dans le provisoire et l'incertain de l'heure, Aïn-Sefra est belle...

\section{Des premières notes:}

Aïn-Sefra, double décor de village français aux pâles verdures telliennes, - peupliers d'argent, platanes débiles, jaunis - et de ksour en toube grise, aux rues inégales et désertes. Au pied des montagnes très hautes et très bleues, les crêtes dentelées des dunes fauves, les ondulations molles du sable roux et l'envahissement de l'alfa houleuse.

3 Rhaïta: musette arabe. 


\section{Soldats d'El Moungar}

Je monte à l'hôpital, dans la redoute qui domine la ville. ${ }^{4}$ Grands bâtiments en briques rouges, entourés de galeries à arcades. Les blessés d'El-Moungar errent à l'ombre, avec des pansements de linge très blanc, dans le désœuvrement de leur convalescence.

Deux ou trois Français, parmi ces étrangers... le reste, Allemands ou Italiens: rudes figures culottées, sourires avenants.

Un peu fiers d'être "interviewés" - un mot qu'on leur a appris - ils sont pourtant intimidés. Alors, bien militairement, ils finissent par m’adresser à leur chef, le caporal Zolli.

Jeune, grand et mince, portant avec aisance la tenue grise de l'hôpital, il parle un français correct, parfois même élégant. Lui, habitué, ne se trouble pas.

Clairement, vivement, il me raconte la halte imprudente, sans aucune précaution, dans la vallée entre El-Moungar et Zafrani, l'insouciance fatale du malheureux capitaine Vauchez qui disait en riant qu'il irait en bras de chemise au Tafilalet, et cela quelques jours avant sa mort... Le caporal atteste pourtant la belle crânerie calme du capitaine qui, mortellement blessé, trouva la force d'écrire quelques mots au crayon pour envoyer prévenir le capitaine de Susbielle, à Taghit.

Dans le récit du caporal passe aussi la mélancolique silhouette de cet officier danois, le lieutenant Selkauhausen, qui était venu servir à la légion étrangère, avec son grade, pour s'instruire, et qui est allé mourir là-bas, dans ce coin ignoré du Sud-Oranais.

- Il paraît que le lieutenant était fiancé dans son pays, ajoute le caporal. C'est égal, c'est bien triste, cette mort-là!

Zolli sait faire revivre les affres de cette journée de lutte acharnée, inégale, loin de tout secours. Il est modeste, n'exagérant pas son propre rôle, avouant la blessure de sa main droite qui, dès le début, l'a empêché de tirer. Ancien soldat du général Menotti Garibaldi, en Macédoine, Zolli aime la guerre: il s'arrange toujours pour être où on se bat.

Parfois, les hommes, plus frustes, s'enhardissent, risquent un mot, quelque souvenir simple et poignant ou quelque plaisanterie sur leur propre infortune.

4 Isabelle Eberhardt, souffrante des fièvres du Sud, devait entrer un an plus tard, en revenant du Maroc, à l'hôpital d'Aïn-Sefra. Elle y passa un mois et n'en sortit convalescente que la veille de la catastrophe du 21 octobre 1904 où elle trouva la mort. L'hôpital d'Aïn-Sefra, placé sur la hauteur, n'eut aucunement à souffrir de l'inondation qui ruina le village. 
- On a eu bougrement soif, ce jour-là, dit l'un d'eux qui ne semble pas se souvenir d'autre chose. Et, comme y avait pas d'eau, on s'est envoyé pas mal de litres de vin pur, le soir, quand ç’a été fini. Alors, ça nous a tapé dans le plafond, et ça fait qu'on était un peu soûls.

Très sympathiques, ces pauvres diables qui ont souffert et failli mourir pour des affaires qui ne sont pas les leurs, et qui les laissent profondément indifférents.

Au rez-de-chaussée, une petite salle peuplée de tirailleurs malades.

Là, couché parce qu'il s'ennuie, Mouley Idriss, un grand mokhazni bronzé, musclé, sec, avec une figure régulière et énergique de nomade.

Ce mokhazni fut blessé quelques jours avant El-Moungar, par un djich. ${ }^{5}$ Très primitif et d'abord très fermé, Mouley Idriss finit pourtant par se rassurer et par sourire. Il exprime ce que pensent tous les Arabes du Sud-Ouest. Pour eux, il n'est question ni de guerre avec le Maroc ni surtout de guerre sainte. La région a toujours été bled-el-baroud (pays de la poudre), et les tribus de la vague frontière se sont toujours razziées les unes les autres. Mouleyidriss désigne l'ennemi d'un nom significatif: el kbian, les voleurs, les bandits. Il considère les opérations militaires actuelles comme des contre-razzias et des représailles sur les djiouch, tout simplement.

Cela explique bien pourquoi les auxiliaires indigènes si précieux, mokhazni, goumiers, cavaliers-courriers, sokhar, ${ }^{6}$ dont la plupart sont recrutés parmi les nomades du pays, n'éprouvent aucune répugnance à combattre les pillards, et donnent l'exemple d'une valeur, d'une endurance et d'un dévouement au-dessus de tout éloge. Mouley Idriss, sans insister sur ce qu'il a eu à souffrir de la part de l'ennemi, réprouve énergiquement les actes de ceux qu'il appelle des coupeurs de routes, des chacals. Au fond, il ne doit pas désirer bien sincèrement que tout cela prenne fin: il est nomade, donc homme de poudre, et il aime se battre.

Mouley Idriss appartient au makhzen de Sidi Mouley ould Mohammed, agha des Amour d'Aïn-Séfra, l'une des personnalités indigènes du Sud-Ouest les plus sympathiques et les plus dévouées à la cause française. Tandis que je cause avec Mouley Idriss, ses compagnons, tirailleurs, nous entourent.

A moitié dévêtus, avec leurs défroques d'hôpital qui leur vont mal et leur tour de tête rasé, ils sont drôles. Ils ont des gamineries et des éclats de rire qui contrastent avec leurs robustes carrures et leurs visages mâles.

5 Djich, au pluriel djiouch, petite bande de pillards armés.

6 Sokhar, conducteur de chameau, caravanier. 
Tout ce petit monde souffrant attend avec impatience le jour où, même mal guéris, on voudra bien les laisser sortir: les Arabes considèrent l'hôpital comme un lieu funeste, comme une prison.

\author{
Notas de viagem: Marrocos-Argélia-Tunísia \\ Sul de Orã \\ Partida da Argélia
}

Aï Sefra, fim de setembro de 1903.

Os últimos dias do verão se desnudavam monótonos. Sob a opressão de um céu sem nuvens, Argel dormia. As ruas, onde os passantes eram raros, pareciam mais largas, e alguns enxames de moscas azuis zumbiam na sombra curta das casas. As colinas de Mustafá se enevoavam de poeiras tênues, e as brancuras leitosas da cidade alta se atenuavam. Lá, entretanto, nos becos estrangulados, a vida continuava ardente, ébria de luz e de cor, com as bancas de frutas e de tecidos, e o canto pensativo dos rouxinóis prisioneiros diante dos cafés mouros.

Um penoso tédio pesava sobre Argel, e eu me deixava ser tomada por uma sonolência vaga, sem alegria e sem pesar, e que, também sem desejos, poderia ter tido a doçura da aniquilação.

Subitamente, a batalha de El-Moungar sobreveio, e, com ela, a possibilidade de rever as regiões ardentes do Sul: eu iria para o Sul da província de Orã, como repórter... O sonho de tantos meses se realizaria, e de forma tão abrupta! mágica.

A longa viagem de trem, através de todo o oeste e sudoeste da Argélia, foi

Na primeira emoção jubilosa da partida, tive algumas horas de repouso e de sonho.

São assim, em certas épocas da vida, os instantes em que nada de extraordinário ocorre, mas que depois a gente jamais esquece, pois são de uma indizível doçura.

Foi em Perrégaux, onde é preciso esperar o trem de Arzew que desce para o Sul.

Perrégaux não é nada mais que um distrito espanhol dividido em grandes jardins verdes, no meio de uma imensa planície fértil. Mesmo assim, esse recanto qualquer do Tell algeriano me pareceu sorridente, quase belo. 
O dia declinava, límpido, sobre a calma do campo. Uma alta colina cortava o horizonte que se incendiava pouco a pouco. No cume, havia uma pequena capela de Sidi Abdelkader de Bagdá, que parecia toda rosada, entre algumas silhuetas de oliveiras cinzentas. Lá, na grama seca, algumas pedras brutas se escondiam: o cemitério muçulmano, um lugar de melancolia calma, sem nada de fúnebre.

...À noite, eu me deitaria sobre uma esteira, diante de um café mourisco. Ao lado, sobre a porta cocheira de um hotel espanhol, lia-se em gordos caracteres mal escritos: Defendido entrar gitanos, "entrada proibida aos ciganos".

Em frente, um muro limpo se perfilava sobre a opala rosada do ocaso. Agachados, alguns árabes nômades sonhavam. No ar quente, aromas conhecidos arrastavam os odores do país beduíno, das noites de verão: fumaça de tuia ou de zimbro, cheiros de couros de bodes, de alcatrão, de carnes curtidas em umidade. E provava a volúpia profunda da vida errante, a alegria de ser só, desconhecida sob o albornoz e o turbante muçulmanos, e de olhar em paz o dia terminar nas cintilações vermelhas sobre a simplicidade das coisas, nesta cidadezinha onde nada me prendia, e que eu abandonaria ao anoitecer.

Em seguida, foram de novo horas longas na janela do vagão, através de lugares sempre mais desertos e mais ardentes, à medida que o pequeno trem lento descia para o Sul.

Cidadezinhas e distritos passaram na noite lunar, rápidos, furtivos, como visões.

Quase no meio da noite, veio-me a visão da triste Saïda, onde tantos destroços humanos vêm buscar o esquecimento sob o teto anônimo da legião estrangeira. Depois, a rude subida dos altos platôs, sobre as curvas dos trilhos. Os dois motores do trem bafejavam, soluçavam como burros ofegantes.

Em cima, na entrada da imensa planura nua, dois marabus gêmeos pareciam vigiá-la.

Algumas paradas em terra aberta, em favor das cidadezinhas que não se viam ou dos longínquos douars: Aïn-el-Hadjar, Bou-Rached, Tafaroua...

Enfim o dia se inflamava, num céu vermelho e verde, sobre as pequenas dunas lívidas do Khreider.

E assim indefinidamente era sempre a monotonia grave, a tristeza, e também o grande encanto pungente da planura do Sul, com seus raros tufos de alfa coriácea e seus arbustos rastejantes, cinzentos sobre o solo sanguíneo. Algumas cadeias de montanhas se esquivavam ao longe, mal se distinguiam de tão diáfanas. 
O sol subiu, e nós chegamos em frente da parada robusta de Djebel-Antar se avançando no indefinido dos horizontes planos. Ao pé desta alta muralha azul surge Mechéria, alguns telhados rosados, algumas escassas árvores amareladas, depois, imediatamente em seguida, nada mais, de novo o vazio da estepe onde se exibiam as claridades iridescentes da manhã..

As estações órfãs tinham, desde Khreider, mudado de aspecto: eram agora feitas de robustas pequenas fortalezas flanqueadas de mirantes cinzentos, fechadas por pesadas portas de ferro.

...Enfim as montanhas surgiram do azul quente das distâncias: DjebelMektar, Mir-el-Djebel, os montes de Sfissifa. Ao longe, para o Oeste, estava o Marrocos.

Grandes dunas avermelhadas subiram atacando Mektar, como ondas de um quebra-mar. Uma faixa de folhagem azulada bloqueava os altos edifícios de tijolos do reduto.

À direita, algumas casas saarianas em adobe, ${ }^{7}$ coladas umas às outras, arvoredos de figos negros, algumas silhuetas de tamareiras, alguns marabus brancos. Nós paramos enfim em Aïn-Sefra, por onde eu deveria apenas passar.

\section{Aïn-Sefra}

Aïn-Sefra, outrora, era uma guarnição de soldados qualquer submersa na sonolência e na rotina da vida militar em tempos de paz. ${ }^{8}$ Atualmente, com os distúrbios do Sul e com a tormenta que ruge de novo através do Marrocos em fermentação, Aïn-Sefra parece despertar, retomar seus aspectos de antes, dos tempos heróicos de Bou-Amama. As tropas mais numerosas, mais ruidosas, as chegadas e as partidas, as esperas, às vezes as angústias, todo um movimento insólito preenche as ruelas de areia.

Misturando-se com o sol, soldados montados em seus pequenos cavalos magros, robustos, mokhazni em longos albornozes negros bordados de vermelho no peito, a cintura eriçada de cartuchos, atiradores azuis, spabi de casaco verme-

7 Toub, adobe árabe. Toub ou toube significa tijolo adobino.

8 Primeiras notas:

Aïn-Sefra, duplo cenário de cidadezinha francesa de pálidos verdores tellianos, - choupos subtropicais, sicômoros débeis, amarelados - e de alcácer em adobe cinzento, de ruas irregulares e desertas. Ao pé das montanhas bem altas e bem azuis, os picos dentados das dunas fulvas, as ondulações moles da areia ruiva e a invasão da alfa turbulenta. 
lho, e os legionários, estes homens brancos do Norte, bronzeados, curtidos por uns sóis longínquos, nas colônias.

Nas cantinas e nos cafés mouros cheios de uma alegre algazarra, os contrastes mais inesperados se chocam. Os dísticos obscenos das músicas de rua, e os serrotes que são uma novidade aqui, se misturam aos sentimentalismos lisonjeiros dos romances alemães ou italianos. E ao lado a velha rhaïta africana chora e grita seus rondéis estranhos, acompanhando melopeias lentas, cortadas, em forma de refrão, de longos gritos desolados.

Em uma mesma embriaguez de movimento e de ruído, os dois mundos vizinhos, o mundo europeu e o mundo árabe, se esbarram, se misturam sem jamais se confundir.

A todas estas dissonâncias, a legião estrangeira vem acrescentar ainda outras notas longínquas. E com toda esta algazarra e todos estes homens, no provisório e imprevisível do horário, Aïn-Sefra é bela...

\section{Soldados de El-Moungar}

Subo ao hospital, no reduto que domina a cidade. ${ }^{10}$ Grandes edifícios de tijolos vermelhos, cercados de galerias com arcadas. Os feridos de El-Moungar deambulam na sombra, com ataduras de tecido bem branco, no tédio da sua convalescência.

Dois ou três franceses, entre esses estrangeiros... o resto, alemães ou italianos: rudes figuras de bermudas, de sorrisos envolventes.

Um pouco orgulhosos de ser "entrevistados" - uma palavra que lhes ensinamos - eles se sentem, entretanto, intimidados. Então, bem militarmente, acabam me dirigindo ao seu chefe, o cabo Zolli.

Jovem, alto e magro, vestindo com desenvoltura o traje cinza do hospital, fala um francês correto, às vezes até mesmo elegante. Ele, como de costume, não se desconcerta.

Clara e vivamente, me fala da paragem imprudente, sem nenhuma precaução, no vale entre El-Moungar e Zafrani, da insensatez fatal do infortunado capi-

9 Rhaïta, gaita de fole árabe.

10 Isabelle Eberhardt, doente das febres do Sul, teve que se internar, um ano mais tarde, voltando do Marrocos, no hospital de Aïn-Sefra. Passou um mês internada e só saiu convalescente na véspera da catástrofe de 21 de outubro de 1904, quando ela morreu. Este hospital, localizado na parte alta da cidade, não sofreu nada quando houve a inundação que arruinou Aïn-Sefra naquele ano. 
tão Vauchez, que dizia rindo que iria vestido à paisana a Tafilalet, e isto alguns dias antes da sua morte... O cabo atesta no entanto a bela bravura calma do capitão que, mesmo estando mortalmente ferido, encontrou forças para escrever algumas palavras a lápis para mandar advertir o capitão de Susbielle, em Taghit.

No relato do cabo passou também a melancólica silhueta desse oficial dinamarquês, o tenente Selkauhausen, que veio servir na legião estrangeira, com seu posto, para aprender, e foi morrer logo naquele recanto ignorado do Sul de Orã.

- Parece que o tenente estava noivo em seu país, acrescenta o cabo. Dá no mesmo, é bem triste essa morte!

Zolli sabe reviver as atribulações desse dia de luta árdua, desigual, longe de qualquer socorro. Ele é modesto, sem exagerar o seu próprio papel, reconhecendo a ferida da sua mão direita que, desde o princípio, o impediu de disparar. Antigo soldado do general Menotti Garibaldi, na Macedônia, Zolli adora a guerra: sempre encontra uma forma de estar onde se combate.

Às vezes, os homens mais rudes se encorajam, arriscam uma palavra, alguma lembrança simples e pungente ou alguma piada sobre o seu próprio infortúnio.

- A gente teve uma sede violenta aquele dia, disse um deles que parece não se lembrar de outra coisa. E, como lá não tinha água, descemos goela abaixo vários litros de vinho puro à noite, quando tudo terminou. Então a bebida subiu e nos sentimos um pouco bêbedos.

Muito simpáticos esses pobres diabos que sofreram e quase morreram por assuntos que não são de seu interesse, e que os deixam profundamente indiferentes.

No térreo, uma pequena sala povoada de atiradores doentes.

Lá, deitado porque se sentia entediado, estava Mouley Idriss, um grande mokhazni bronzeado, musculoso, brusco, com a figura regular e enérgica de um nômade.

Esse mokhazni foi ferido uns dias antes de El-Moungar, por um djich. ${ }^{11}$ Muito primitivo e no início muito fechado, Mouley Idriss acabou se abrandando e sorrindo. Ele exprime o que pensam todos os árabes do Sudoeste. Para eles, não se trata de uma guerra com o Marrocos, nem, sobretudo, de uma guerra santa. A região sempre foi a fortaleza-da-pólvora (o lugar da pólvora), e as tribos da vaga

11 Djich, no plural djiouch, pequena banda de saqueadores armados. 
fronteira sempre estão fazendo razias umas contra as outras. Mouley Idriss designa o inimigo de um nome significativo: el kbian, ou seja, os ladrões, os bandidos. Considera as operações militares atuais como contrarrazias e como represálias contra os djiouch simplesmente.

Isto explica bem por que os auxiliares nativos tão valiosos, os mokhazni, soldados, mensageiros a cavalo, sokhar, ${ }^{12}$ dos quais a maioria está recrutada entre os nômades do país, não experimentam nenhuma repugnância para combater os saqueadores, e dão o exemplo de um valor, de uma resistência e de uma dedicação acima de qualquer elogio. Mouley Idriss, sem insistir sobre o que ele teve que sofrer nas mãos do inimigo, reprova energicamente os atos daqueles que ele chama de saqueadores de estrada, de chacais. No fundo, ele não deve desejar, sinceramente, que tudo isto tenha fim: é nômade, portanto um homem de poeira que ama lutar.

Mouley Idriss pertence ao makhzen de Sidi Mouley ould Mohammed, chefe da tribo Amour de Aïn-Séfra, uma personalidade natural do Sudoeste das mais simpáticas e mais dedicadas à causa francesa. Enquanto eu conversava com Mouley Idriss, seus companheiros, atiradores, nos rodeavam.

Metade desnudos, com seus uniformes do hospital que lhes caem mal e com suas cabeças raspadas, eles são engraçados. Vivem fracassos e dão gargalhadas que contrastam com seus robustos ombros e suas caras varonis.

Todo esse pequeno mundo desgastado espera com impaciência o dia em que, mesmo mal curados, lhes deixem sair: os árabes consideram o hospital como um lugar funesto, como uma prisão.

\section{Referências}

CORRÊA, Roberto Alvim; STEINBERG, Sary Hauser. Dicionário escolar francês-português, português-francês. 7. ed. Rio de Janeiro: FAE-MEC, 1986.

EBERHARDT, Isabelle. Notes de route: Maroc-Algérie-Tunisie. Paris: Librairie Charpentier et Fasquelle, 1908, p. 15-28. Texto integral: <http://archive.org/details/notesderoute maro00eberuoft>

HOUAISS, Antônio. Dicionário Eletrônico Honaiss da Lingua Portuguesa. Rio de Janeiro: Objetiva, 2009.

12 Sokhar: condutor de camelo, caravaneiro. 
MARIUZZO, Patrícia. “Árabes no Brasil”. In: Ciência e Cultura. vol. 63, no 3. São Paulo, julho de 2011. < http:/ / cienciaecultura.bvs.br/scielo.php?pid=S0009-67252011000300022 \&script $=$ sci_arttext $>$.

ROBERT, Paul. Le petit Robert 1: dictionnaire alphabétique et analogique de la langue française. Paris: Le Robert, 1990.

id. Le petit Robert 2: dictionnaire de culture générale. Paris: Le Robert, 1993.

\section{Websites}

Dicionário Sensagent (37 idiomas). www.sensagent.com

Enciclopédia Wikipedia. www.wikipedia.com 